\title{
UMA Leitura EnUNCIATIVA da Língua Brasileira de Sinais: O GÊnero Contos de Fadas
}

\author{
(An Enunciative Reading of the Brazilian Sign Language: \\ The Fairy Tales Genre)
}

\author{
Ana Claudia Balieiro LodI \\ (Pontifícia Universidade Católica de São Paulo - PUC-SP \\ Universidade Metodista de Piracicaba - Unimep)
}

\begin{abstract}
This article refers to an initial study of the discoursive processes of the Brazilian Sign Language (LIBRAS) in the fairy tales genre under the light of the enunciative theory of Bakbtin. Current analysis data, although in its early stages, pointed out some relevant discoursive aspects about LIBRAS, mainly those related to the constitution of its interdiscursive dynamic. It refers to the understanding of how the different voices present in the text are built, how they differ in their compositional aspects, how they assimilate the discourse of other, and how they interrelate to each other and to the full context regarding the approach of the theme.
\end{abstract}

KEY-WORDS: Bakhtinian's enunciative theory; Brazilian Sign Language (LIBRAS); discoursive genre; fairy tales.

REsumo: Este artigo refere-se a um estudo inicial dos processos discursivos da língua brasileira de sinais (LIBRAS), no gênero contos de fadas, à luz da teoria enunciativa de Bakbtin. As análises realizadas, embora iniciais, apontaram alguns aspectos discursivos relevantes sobre a LIBRAS, principalmente no que se refere à dinâmica interdiscursiva que a constitui, ou seja, à compreensão de como as diferentes vozes presentes nos textos são construídas, como elas se diferenciam quanto aos aspectos composicionais, como assimilam o discurso do outro e como se inter-relacionam entre si e com o todo textual para o tratamento do tema.

PALAVRAS-CHAVE: teoria enunciativa bakbtiniana, lingua brasileira de sinais (LIBRAS), gênero discursivo, contos de fadas. 


\section{Introdução}

Durante a década de 1950, assistiu-se a um movimento que visava distinguir as línguas das linguagens artificiais e lógico-matemáticas, sendo prática corrente a utilização do termo "natural" ao referir-se às primeiras como forma de garantir sua autenticidade (cf.: Rée, 1999). As línguas de sinais, neste período, ainda eram tidas como linguagens artificiais, pois se tinha em mente que estas tomavam como base as línguas orais, eram subordinadas a sua gramática, sendo, portanto, uma transposição destas línguas ao espaço a partir de uma materialidade viso-manual.

Esta concepção equivocada das línguas de sinais foi determinada, em grande parte, pelo método francês de educação dos surdos, desenvolvido em meados do século XVIII pelo abade Charles Michel de l'Epée. De l'Epée acreditava que a língua de sinais era desprovida de gramática e, assim, criou, para o desenvolvimento da educação dos surdos, alguns sinais sinais metódicos - com o objetivo de suprir a falta de elementos observada na língua de sinais quando na comparação com o francês e de possibilitar a submissão da língua de sinais a regras (no caso as da gramática francesa).

Foi somente em 1957, determinado, sobretudo, pelas idéias de Saussure, que Stokoe, professor do Gallaudet College em Washington, levantou como hipótese que as línguas de sinais dos surdos poderiam ser consideradas "naturais" e, portanto, instrumento lingüístico propriamente dito no sentido mais geral dado por Saussure (cf.: Behares, 1993; Rée, 1999). Assim, em 1960, ele concluiu a primeira descrição de uma língua de sinais, mais especificamente, da American Sign Language (ASL). Este estudo influenciou sobremaneira a educação dos surdos e tornou-se a base para que outras pesquisas em distintos países fossem desenvolvidas, e assim, a descrição lingüística das diferentes línguas de sinais existentes realizada.

Dessa forma, as línguas de sinais deixaram de ser tratadas como um conjunto de símbolos visual-manuais desarticulados e passaram a ser concebidas como "uma estrutura multiarticulada e multinivelada, com base nos mesmos princípios gerais de organização que podem ser encontrados em qualquer língua" (Behares, 1993: 43). Além disso, comprovou-se que ao utilizá-la, são satisfeitas as mesmas funções e obtidos "os mesmos rendimentos processuais que se podem alcançar na utilização das línguas orais, mais antigamente conhecidas e reconhecidas" (Behares, 1993: 43). 
Nota-se, no entanto, que a maioria dos estudos realizados sobre as línguas de sinais no decorrer da história compartilha um paradigma comum, buscando sua descrição segundo os mesmos parâmetros e a mesma organização em níveis lingüísticos conforme propostos por Stokoe (1960).

Este artigo propõe um deslocamento deste olhar a partir da realização de uma leitura preliminar dos processos discursivos da língua brasileira de sinais (LIBRAS) no gênero contos de fadas, à luz da teoria enunciativa de Bakhtin. Torna-se importante salientar que com esta (re)leitura, não se está negando o incomensurável valor dos estudos anteriores, pois, graças a eles, as línguas de sinais passaram a ser reconhecidas em seus respectivos países, a circularem nos meios acadêmicos e a serem consideradas como fundamentais para a educação dos surdos. Trata-se apenas de um novo olhar para ela, atribuindo-lhe novas significações, que vêm se somar às discussões anteriormente realizadas por outros autores.

\section{Os estudos sobre as línguas de sinais e a teoria enunciativa de Bakhtin}

Ao discutir as linhas mestras do pensamento filosófico-lingüístico, Bakhtin/Volochinov (1929) descreve duas orientações: o subjetivismo idealista e o objetivismo abstrato ${ }^{1}$.

Para os objetivistas abstratos, o centro organizador dos fatos da língua encontra-se no sistema lingüístico, ou seja, no sistema das formas fonéticas, lexicais e gramaticais da língua. Esse sistema é, segundo Bakhtin/ Volochinov (1929), regido por leis imanentes e específicas, essencialmente lingüísticas, que estabelecem, no interior do próprio sistema, ligações e relações entre os signos lingüísticos.

Ao lingüista cabe determinar as unidades e as regras de combinações que constituem o sistema, identificando os elementos decisivos para a função significante da língua, ou seja, aqueles que são funcionais dentro do próprio sistema. Para a realização de tal estudo, o lingüista deve adotar uma perspectiva sincrônica, pois como o signo, arbitrário em essência, não

\footnotetext{
1 Por ser nesta corrente que se inscreve a maioria dos estudos sobre as línguas de sinais, as discussões que aqui se iniciam estarão restritas a esta segunda orientação. Os interessados numa discussão sobre a primeira corrente devem remeter-se a Bakhtin/Volochinov (1929).
} 
tem nenhum núcleo que deva persistir na história da língua, ele constituise como uma entidade relacional, isto é, o signo define-se pela sua relação com os outros signos no interior do sistema lingüístico (cf.: Culler, 1979).

Como sistema fechado e constituído a priori numa dada comunidade lingüística, a língua impõe-se aos indivíduos como norma e, assim, qualquer mudança neste sistema ultrapassa a consciência individual; portanto, é um sistema que o indivíduo deve tomar e assimilar no seu conjunto tal como ele é. Dessa forma, a língua é concebida como um sistema estável e imutável de formas lingüísticas, responsáveis pela garantia de sua unicidade.

Partindo destes pressupostos, em 1960, William Stokoe publicou o primeiro estudo sobre uma língua de sinais descrevendo a estrutura da American Sign Language (ASL) a partir da análise de seus elementos constituintes. Assumindo o pressuposto saussureano de que existem princípios gerais comuns a todas as línguas, Stokoe (1960) descreveu o sistema da ASL tomando como base os sistemas descritos para as línguas orais.

Propôs, então, um sistema - quirologia - cuja função seria análoga à desempenhada pelo sistema fonológico nas línguas orais. Os quiremas foram selecionados e analisados a partir do contínuo de movimentos gestuais (da mesma forma como os fonemas foram selecionados da infinidade de sons vocais possíveis), identificados e descritos em três tipos: posição (ponto de articulação), configuração e movimento da mão.

Todos os sinais foram analisados a partir da combinação dos três quiremas (em suas diversas combinações). Os sinais por eles formados, tidos como as unidades responsáveis pela composição do sistema sintático da ASL, assim como as palavras o são nas línguas orais, consistem nos morfemas da ASL. Eles são, então, as menores unidades da língua que contém significado e, por isso, passíveis de serem isolados do sistema quando na descrição lingüística da ASL.

Dessa forma, Stokoe (1960), centrando seu trabalho na descrição dos sinais e na função que eles exercem na ASL, concluiu que "a atividade comunicativa das pessoas que usam esta língua [a ASL] é verdadeiramente lingüística e suscetível a análise micro-lingüística do tipo mais rigoroso" (Stokoe, 1960: 67).

O impacto do estudo de Stokoe (1960) foi tal que, a partir dele, nos anos subseqüentes, diversas línguas de sinais passaram a ser descritas se- 
guindo, em sua grande maioria, a mesma classificação proposta por este autor, ou seja, em níveis lingüísticos (particularmente, em níveis fonológico, morfológico e sintático). Assim ocorreu com as línguas de sinais inglesa, chinesa, costarriquenha, tcheca, venezuelana, iugoslava (cf.:Rée, 1999), francesa, sueca, dinamarquesa, holandesa, alemã, italiana (cf.:Johnson, 1994), portuguesa (cf.: Amaral, Coutinho \& Martins, 1994) e também com a brasileira (cf.: Ferreira-Brito, 1995; Quadros, 1997; Quadros \& Karnopp, 2004), além de uma vasta quantidade de estudos sobre a língua de sinais americana (cf.: Klima \& Bellugi, 1979; Poizner, Klima \& Bellugi, 1987; Emmorey, Bellugi \& Klima, 1993, dentre vários outros citados nos estudos das diferentes línguas de sinais).

Torna-se importante acrescentar, entretanto, que estes estudos embora tenham seguido o modelo de descrição proposto por Stokoe (1960), não se configuraram apenas como uma reprodução passiva e estática deste trabalho, mas sim, buscaram aspectos diferenciais e específicos desta nova língua que a eles se apresentava, complementando e aprofundando o conhecimento gramatical sobre ela. Estes aspectos referem-se, por exemplo, à proposição de outro parâmetro fonológico - orientação da palma da mão - por Battison, nos anos 70 (cf.: Souza, 1998), complementando os três descritos por Stokoe (1960); à descrição de parâmetros secundários na organização fonológica dos sinais, como a disposição da mão (articulação realizada pela mão dominante ou pelas duas mãos), a orientação da(s) mão(s) e a região de contato (cf.: Klima \& Bellugi, 1979) e, no nível sintático da língua, as relações pronominais e verbais desenvolvidas no espaço de enunciação (cf.: Klima \& Bellugi, 1979; Poizner, Klima \& Bellugi, 1987; Emmorey, Bellugi \& Klima, 1993; Amaral, Coutinho \& Martins, 1994; Ferreira-Brito, 1995; Quadros, 1997; Quadros \& Karnopp, 2004).

No entanto, a busca de paridade entre o conhecimento lingüístico das línguas de sinais e aquele das línguas orais permaneceu. Nesta direção, foram realizadas discussões sobre a maneira como os sinais se organizam nas sentenças em língua de sinais em oposição à mesma organização nas línguas orais. Melhor dizendo, conforme apontaram Klima \& Bellugi (1979), dada a diferença de canal de transmissão entre as línguas de sinais (visual-gestuais) e as línguas orais (auditivo-orais), constatou-se que as línguas sinalizadas permitem que seus elementos se organizem a partir da combinação de unidades que ocorrem simultaneamente, ou seja, os sinais podem ser realizados por uma ou pelas duas mãos no mesmo espaço de 
tempo. Esta organização opõe-se à das línguas orais, que se constituem seguindo uma organização temporal sucessiva, seqüencial.

Massone (1993), ao descrever e comentar os caminhos escolhidos pelos lingüistas interessados no conhecimento das línguas de sinais, criticou a tendência de permanência destes estudos à sombra daqueles tradicionalmente desenvolvidos e pensados para as línguas orais, questionando:

Até que ponto as linguas de sinais podem ser entendidas dentro do marco convencional da lingüística, quer dizer, tomando como pontos de referências teóricos modelos que foram projetados para linguas baseadas nos sons e derivados de formas lingüísticas formalizadas? (...) Os modelos que provêm da lingüística tradicional e ocidental são suficientes para a análise das línguas de sinais? Podem as línguas de sinais ser descritas nos mesmos termos das línguas faladas? (Massone, 1993: 81-82).

Para a autora, o fato das línguas de sinais possuírem uma materialidade distinta e, portanto, uma organização diversa à das línguas orais deve, obrigatoriamente, promover um deslocamento na forma de estudá-la.

A maioria dos lingüistas bavia descrito linguas faladas, todos eram ouvintes (...) Quando aceitaram o desafio de analisar uma língua numa modalidade diferente, deveriam reestruturar sua forma de pensar já que estavam tratando com um objeto que, além de não ser a sua língua nativa, era uma lingua transmitida numa modalidade visuo-gestual (Massone, 1993: 82).

O resultado inicial desta busca pela descrição das línguas de sinais a partir do modelo previsto para as línguas orais foi a obtenção de conclusões que descreviam e/ou apontavam o que "faltava" a essas línguas, ou seja, às línguas de sinais foram atribuídas carências de artigos e de preposições, de marcadores de número e gênero, bem como de processos morfológicos de tempo e modo verbal. Posteriormente, ao haver uma maior aceitação das línguas de sinais, suas especificidades gramaticais passaram a ser descritas e respeitadas; no entanto, manteve-se subjacente a esses estudos a idéia da existência de um princípio lingüístico universal e, portanto, acreditava-se que as constatações e os novos conhecimentos obtidos em uma língua de sinais estivessem também presentes em todas as demais línguas de sinais. Sem negar a extrema relevância destes estudos para um conhecimento mais aprofundado das línguas de sinais, cabe assinalar que seus objetivos eram a descrição dos aspectos gramaticais específicos das mesmas, sem levar em consideração suas particularidades discursivas, sua forma de organização em cada contexto e em cada enunciação particular. 
Este estudo, ao adotar uma perspectiva enunciativa para o estudo da LIBRAS, assume um olhar que difere dos trabalhos comentados acima. Ao conceber a língua como uma corrente evolutiva ininterrupta, tem-se, como pressuposto, que ela não pode ser considerada se isolada de sua história, pois a língua vive e evolui historicamente na comunicação verbal. Considera-se assim, que a palavra deve ser estudada no seu campo vivo, constantemente ativo e mutável, pois sua vida está na relação interdiscursiva dinâmica estabelecida entre membros de uma mesma comunidade lingüística; ela sofre transformações dependendo do grupo social que a usa, ela se altera segundo o contexto discursivo que a integra.

É por este motivo que, para Bakhtin (1929), a palavra deve sempre ser interpretada e tomada como signo e, portanto, não no campo da língua, mas sim no da linguagem. Toda a vida da linguagem está impregnada de relações dialógicas e estas existem, apenas, se materializadas no discurso, se personificadas na linguagem, se tornadas enunciados, convertendose em diferentes posições de diferentes sujeitos expressas na linguagem.

O enunciado, dessa forma, só existe na cadeia de comunicação verbal e, nesta, é delimitado e constituído por outros enunciados. Assim, o enunciado nunca é único e monológico, pois antes dele há os enunciados dos outros e, após o seu final, os enunciados respostas dos outros, constituindo-se, assim, na esfera do já-dito ao mesmo tempo em que se orienta para o ainda não dito.

Do ponto de vista da teoria bakhtiniana, um discurso define-se, unicamente, se na relação com outros discursos, no limite de um mesmo contexto; é um fenômeno social de interação verbal realizada através de processos enunciativos; e qualquer enunciação é apenas uma fração de uma corrente verbal que constitui um momento evolutivo contínuo e, portanto, histórico, de um grupo social determinado.

A comunicação verbal não poderá jamais ser compreendida e explicada fora desse vínculo com a situação concreta. A comunicação verbal entrelaça-se inextricavelmente aos outros tipos de comunicação e cresce com eles sobre o terreno comum da situação de produção ${ }^{2}$ (Bakhtin/ Volochinov, 1929: 124).

2 Ênfase adicionada. 
No entanto, observa-se nos estudos sobre as línguas de sinais, que ainda há uma tendência a se considerar as enunciações excluidas do todo discursivo, como por exemplo, as descrições e discussões realizadas sobre as relações que ocorrem no espaço de enunciação visando a compreensão de como são estabelecidas as relações sintáticas, como as de (co)referência e de concordância verbal e pronominal ${ }^{3}$. Estes aspectos lingüísticos, embora bastante relevantes para a compreensão do sistema, podem contribuir apenas em parte, para a compreensão discursiva das línguas de sinais, na medida em que não são consideradas as relações da enunciação com a situação e com os outros enunciados. Perde-se, assim, a essência dialógica da linguagem, ou seja,

3 Segundo Ferreira-Brito (1995), os sistema pronominais da LIBRAS têm, como ponto central de organização, um sistema de orientação determinado por localizações espaciais específicas dentro do espaço de enunciação. A autora diferenciou três níveis espaciais: "1) a localização como componente interno da estrutura de um sinal; 2) a localização como parte do espaço de enunciaçãa usado como a estrutura lingüística para os pronomes (interpretação espacial lingüística dos referentes); 3) a localização real dos participantes conversacionais e dos referentes de terceira pessoa" (Ferreira-Brito, 1995: 92). Estes três níveis são coincidentes para a referência de primeira pessoa; para referência de segunda pessoa, as diferenciações nos três níveis, por não causarem impacto na realização do sinal, têm a localização obscurecida. No caso da referência de terceira pessoa, o primeiro nível é distinguido pelo olhar ou pela orientação do olhar, garantindo a diferenciação entre os referentes de segunda e terceira pessoas. No segundo nível, a localização da terceira pessoa pode ocorrer: a) como projeções verticais no espaço de enunciação sem sobreposição aos referentes de primeira e segunda pessoas; e b) através do uso do corpo do enunciador que se desloca em direção à localização de terceira pessoa. No terceiro nível, em casos de referentes presentes, aponta-se para a área na qual a pessoa está localizada; com referentes não-presentes, a referência é realizada pela associação da pessoa a pontos do espaço determinados pela situação conversacional. Em alguns casos os pronomes podem também ser incorporados aos sinais através das relações estabelecidas com determinados verbos, como pode ser observado a seguir.

Os verbos em LIBRAS, conforme descreveu Quadros (1997), podem ser divididos em três classes: 1) os que se flexionam em pessoa e em número não utilizando afixos locativos (verbos conhecer, amar, aprender, saber, gostar,...); 2) os verbos espaciais que possuem afixos locativos (verbos viajar, ir, chegar,...); e 3) os denominados verbos de concordância ou direcionais, únicos que se flexionam em pessoa e em número sem tomar afixos locativos (verbos dar, responder, perguntar, ajudar, dizer...). Esta última classe de verbo possibilita a incorporação pronominal através da mudança de direção/ movimentação do verbo no momento da enunciação. Quadros \& Karnopp (2004) acrescentaram a esta classificação uma outra classe de verbos denominada handling verbs ou verbos manuais. Nestes, utiliza-se uma configuração de mão em que se representa o segurar do objeto a que se está fazendo referência (ex.: pintar-a lápis; pintar-a-pincel). Esses verbos, segundo as autoras, são utilizados na finalização da sentença, após a contextualização sobre o que se está falando. Inclui-se nesta classe de verbos os classificadores, que incorporam a informação verbal da sentença e, quando necessário, o objeto. 
o elemento que instaura a constitutiva natureza interdiscursiva da linguagem (...) [e que] diz respeito às relações que se estabelecem entre o eu e o outro nos processos instaurados historicamente pelos sujeitos, que, por sua vez, instauram-se e são instaurados por esses discursos (Brait, 1997: 98).

Para Bakhtin (1970-1971/1979), todas as palavras, exceto as do próprio sujeito, são palavras de um outro e toda sua existência se materializa neste universo de encontro com a palavra do outro, do reagir a elas, de assimilá-las como suas. Assim, pelo princípio dialógico:

A minha palavra está inexoravelmente contaminada do olhar de fora, do outro que lhe dá sentido e acabamento. Em suma, no universo bakhtiniano nenhuma voz, jamais, fala sozinha. E não fala sozinha não porque estamos, vamos dizer, mecanicamente influenciados pelos outros - eles lá, nós aqui, instâncias isoladas e isoláveis - mas porque a natureza da linguagem é inelutavelmente dupla (Tezza, 1997: 221).

Esta dupla orientação do signo lingüístico foi a base sobre a qual Bakhtin desenvolveu seu estudo sobre as vozes presentes no romance. Para ele, o plurilingüísmo introduzido no romance é "o discurso de outrem na linguagem de outrem" (Bakhtin, 1934-1935/1975:127), o encontro de duas consciências lingüísticas de dois sujeitos assimetricamente dispostos: aquele que é representado e aquele que representa. A palavra do discurso é, portanto, bivocal em essência.

Ela [a palavra bivocal] serve simultaneamente a dois locutores e exprime ao mesmo tempo duas intenções diferentes: a intenção direta do personagem que fala e a intenção refrangida do autor. Nesse discurso há duas vozes, dois sentidos, duas expressões. Ademais, essas duas vozes estão dialogicamente correlacionadas, como que se conbecessem uma à outra (como se duas réplicas de um diálogo se conbecessem e fossem construídas sobre esse conbecimento mútuo), como se conversassem entre si (Bakhtin, 1934-1935/1975: 127).

Dessa forma, o autor não pode destruir completamente a outra voz; esta conservará sempre um certo grau de autonomia, não podendo ser completamente diluída no contexto discursivo do autor. Tanto o discurso de outrem quanto o contexto de transmissão unem-se por relações dinâmicas, complexas e tensas, e são responsáveis pela constituição do texto.

Um outro conceito central na teoria bakhtiniana e que, portanto, não pode ser desconsiderado ao assumir uma perspectiva enunciativa, é o de gêneros do discurso. Os gêneros nos são dados como nos é dada nossa língua 
materna, ou seja, "nós a adquirimos mediante enunciados concretos que ouvimos e reproduzimos durante a comunicação verbal viva que se efetua com indivíduos que nos rodeiam" (Bakhtin, 1952-1953/1979: 301).

Desta maneira, as formas da língua, assim como os gêneros do discurso, são introduzidos em nossa experiência e consciência sem que sua correlação seja rompida, pois ambos organizam nossa fala: nossa fala é modulada pelos gêneros discursivos e todas as nossas enunciações revelam as escolhas das formas da língua. Entretanto, se em comparação a elas, os gêneros mostram-se mais flexíveis: eles variam conforme as circunstâncias, a posição social e a relação entre os parceiros da enunciação. Assim, dependendo da especificidade do gênero, há a seleção das palavras a serem utilizadas no discurso; elas são tiradas de outros enunciados (do próprio locutor e do de outros) pela semelhança com o gênero em questão, isto é, pelo tema, pela composição e pelo estilo.

Como em cada esfera de utilização da língua, nos enunciados produzidos, entrelaçam-se várias vozes sociais, o gênero deve ser compreendido como um conceito plural que "reporta-se às formações combinatórias da linguagem em suas dimensões verbal e extra-verbal. Além disso, articula formas discursivas criadoras da linguagem, de visões de mundo e de sistemas de valores configurados por pontos de vista determinados" (Machado, 1997:143).

Souza (1998) já havia comentado a falta de estudos sobre a LIBRAS que considerassem as operações lingüísticas com e sobre a linguagem, ou seja, que tomassem como objeto o uso que os surdos fazem dessa língua em seus grupos de contato (comunidades e organizações). Apontou, ainda, para a necessidade de desenvolvimento de estudos sobre as línguas de sinais em uma perspectiva enunciativa, discutindo que, ao se tomar como base a ordem metodológica de investigação lingüística proposta por Bakhtin/ Volochinov (1929), os estudiosos das línguas de sinais seriam menos influenciados por conceitos prévios, podendo, assim, desvelar aspectos que são ocultados por categorias já constituídas. Dessa forma, um redirecionamento dos estudos sintáticos poderia ser feito ao se olhar para a LIBRAS no acontecimento enunciativo, no imbricamento entre o sintático e o discursivo ${ }^{4}$.

\footnotetext{
4 Embora a LIBRAS como objeto de estudo não tenha sido o foco de seu trabalho, Sá (1998), ao analisar uma entrevista realizada com um surdo adulto, discutiu a polifonia e a heterogeneidade constitutiva da linguagem - em LIBRAS - apontando também para a necessidade do desenvolvimento de estudos sob uma perspectiva discursiva.
} 
Nesta perspectiva, Pereira (2001) e Pereira \& Nakasato (2001, 2002) têm desenvolvido estudos que visam a compreensão dos processos de construção de narrativas em LIBRAS por crianças surdas, discutindo os aspectos verbais e não-verbais constitutivos desta língua e o uso que as crianças fazem desses aspectos durante seu processo de desenvolvimento da linguagem. Demonstram, nestes estudos, que as crianças surdas quando expostas à LIBRAS por um adulto surdo usuário desta língua, passam a fazer uso "de recursos cada vez mais complexos, como sinais simultâneos e mapeamento do espaço, recursos estes que, combinados às expressões facial e corporal, foram usados na articulação dos fatos nos relatos" (Pereira \& Nakasato, 2002: 75). Enfatizam, assim, a necessidade das crianças surdas serem inseridas no funcionamento lingüístico da LIBRAS o mais cedo possível e demonstram a importância da narrativa de histórias para o processo de desenvolvimento da linguagem destas crianças.

Entretanto, não foi encontrada na literatura pesquisada específica sobre os estudos em línguas de sinais nenhum trabalho que considerasse as particularidades dos diferentes gêneros discursivos nestas línguas. Os estudos que têm sido desenvolvidos, principalmente, nas esferas educacionais, valorizam a necessidade de exposição das crianças surdas à narrativas em LIBRAS, como base para que estas crianças possam se apropriar da linguagem escrita do português; em sua maioria os textos escolhidos são do gênero contos de fadas (cf.: Gesueli, 2000; Pereira, 2001, 2002; Pereira \& Nakasato, 2001, 2002).

Nesta direção, no contexto educacional universitário, teve início, no ano de 2002, pelo Programa de Assessoria Comunitária da Universidade Luterana do Brasil (ULBRA), um projeto cujo objetivo é registrar e catalogar, em vídeo e em material impresso, histórias contadas por e para surdos em LIBRAS, além de investigar as práticas e os processos de leitura e produção de textos por surdos quando no contar histórias, a fim de que o ensino destes sujeitos possa ser realizado desviando-se o foco dos aspectos unicamente gramaticais. Conforme descreveram Alves \& Karnopp (2002), uma equipe formada por um professor, quatro estudantes surdos e um ouvinte, todos da ULBRA, selecionou contos de fadas que, após cuidadosa leitura, sofreram um processo de adaptação: o conto tradicional para ouvintes foi transformado em uma história voltada ao contexto cultural dos surdos. Como exemplo, os autores apresentam a substituição do sapatinho de cristal de Cinderela pela luva branca, indicando que, na nova versão do 
conto - Cinderela Surda - o foco voltou-se para as mãos que sinalizavam: "surdos recontam histórias para outros surdos e reconstroem, através da língua e da cultura, os sentidos veiculados pelo texto que serviu como ponto de partida para a criação de um outro texto" (Alves \& Karnopp, 2002: 72).

Recentemente, foi realizado, também, um vídeo por Andréa Iguma Chapeuzinho Vermelho - a Surda - como trabalho de conclusão de curso de graduação da Escola de Comunicações e Artes (USP) junto ao Projeto de Integração das Tecnologias de Comunicação ao Processo de Letramento do Surdo, em parceria com a Escola do Futuro (USP) e a EMEE Anne Sullivan (SME/PMSP). Nesse vídeo, a história é contada por um surdo e, acompanhando a narração, há a história representada por personagens feitos por papel manipulados com arames (Biblioteca Virtual do Estudante Brasileiro, s/ data).

Esses materiais desenvolvidos têm uma importância impar para o processo de letramento das crianças surdas, na medida em que possibilitam que essas crianças possam entrar em contato com os contos de fadas por meio de materiais em LIBRAS e que lhes são acessíveis por serem desenvolvidos por intermédio de recursos visuais. No entanto, o foco desses estudos é a compreensão e reflexão sobre a prática de ensino-aprendizagem do português (linguagem escrita) e/ou a descrição das questões relacionadas à identidade do grupo de surdos e não os processos discursivos particulares da LIBRAS.

Considerando que o conhecimento dos processos enunciativos em LIBRAS torna-se central para o processo de letramento das crianças surdas, que podem, no contato com a língua em funcionamento, constituírem-se autores/interlocutores de suas próprias histórias, e terem o ensino-aprendizagem do português como segunda língua mediado por um conhecimento específico de sua primeira - a LIBRAS -, este estudo foi realizado. Buscou-se, no presente artigo, a discussão dos aspectos enunciativos específicos e particulares da LIBRAS no gênero contos de fadas e, portanto, a descrição de como são estabelecidas as relações discursivas neste gênero, visando explicitar as particularidades do estilo e das formas composicionais utilizadas para o tratamento do tema do discurso nesta língua.

Cabe salientar, uma vez mais, que este estudo não tem a pretensão de esgotar a descrição deste gênero em LIBRAS e, muito menos, realizar generalizações para outros gêneros discursivos nesta língua, mas sim, trata- 
se de um estudo inicial que deve ser complementado por outros, visando tanto o aprofundamento deste gênero como o conhecimento dos processos enunciativos utilizados em outros gêneros discursivos em LIBRAS.

\section{O gênero contos de fadas em libras}

Para a realização do presente estudo foram analisados dois textos do gênero contos de fadas em LIBRAS - Chapeuzinho Vermelho e Os Três Porquinhos - sinalizados por um surdo reconhecido pela comunidade surda de São Paulo e do Rio de Janeiro como fluente e conhecedor da LIBRAS $^{5}$. Nestes foram observados alguns aspectos que explicitam a forma composicional particular desenvolvida em LIBRAS quando no tratamento do tema do gênero. Entretanto, dadas as especificidades decorrentes de sua materialidade viso-manual, torna-se necessária a realização de uma breve explicação sobre o espaço discursivo utilizado por esta língua, a fim de garantir uma maior compreensão das questões que aqui serão discutidas.

Todo enunciado em LIBRAS é realizado no espaço de enunciação: um semicírculo virtual cujo perímetro é usado para a realização de referência às pessoas do discurso nas situações discursivas com referentes não-presentes (cf.:Ferreira-Brito, 1995) ou presentes (cf.: Quadros, 1997). O corpo do sinalizador deve situar-se no centro do raio do semicírculo e, neste espaço, nas diferentes situações discursivas, podem ocorrer mudanças quanto a direção e a localização de seu corpo, a sinalização em direção a um locus pré-determinado como marca de referência a uma pessoa e/ou objeto e a movimentação ocular para este mesmo local (ao fazer referência à pessoa e/ ou ao objeto ali referido). Estes fenômenos, segundo Massone (2000), servem para o sinalizador indicar diferentes referentes ou para lhes fazer referência anafórica.

Pereira (2001) comenta ainda que é no espaço de enunciação que ocorrem as representações da interação entre os referentes - diálogos e ações desenvolvidas por meio da mudança de posição de referência, ou seja, do narrador para um personagem como primeira pessoa. Para a autora, é também nesse espaço que os eventos temporais são marcados e distinguidos, possibilitando, ao enunciador, a referência a estes eventos pela movimentação no espaço.

Vídeo comercial Literatura em LSB. Califórnia/Rio de Janeiro: Dawn Pictures/LSB Vídeo, 1998. 
Nos dois textos analisados para este estudo, observou-se que as vozes ${ }^{6}$ dos personagens e do narrador são marcadas segundo o lugar que cada um ocupa no espaço de enunciação, estando o narrador no centro do raio do semicírculo e os personagens ou a sua direita ou a sua esquerda.

Massone (2000), ao discutir as referências espaciais na língua de sinais argentina (LSA) em situações de diálogo e monólogo espontâneos, narrações e contos humorísticos, apontou que os dados obtidos em sua pesquisa demonstraram que o locus referencial das pessoas do discurso não é fixo; ele se alterna continuamente dentro do espaço sinalizador dependendo do contexto em que se encontra. A autora complementa suas análises apontando que as relações referenciais em LSA seguem uma hierarquia determinada discursivamente e, para melhor explicar a dinâmica destas relações, a autora fez uma analogia com a organização espacial das cenas de um filme cinematográfico:

Este aspecto é muito difícil de ser equiparado com os traços semióticos da língua verbal, mas facilmente assimilável aos distintos planos referenciais assinalados no cinema: em frente corresponderia, nesta comparação, ao primeiríssimo primeiro plano, à direita o primeiro plano e à esquerda o fundo. (Massone, 2000: 106).

Os textos do gênero contos de fadas observados indicaram também uma hierarquia na ordem de apresentação dos personagens em cada contexto particular (e, portanto, um movimento interdiscursivo determinado pela localização dos enunciadores), ou seja, as pessoas (personagens) assumiam, inicialmente, um locus enunciativo determinado, mas, dependendo do contexto discursivo em que se encontravam, mudavam de lugar e de posição. Essas mudanças, no entanto, não ocorriam de forma aleatória; havia uma organização interna ao discurso que orientava e determinava as mudanças, numa atualização e manutenção constante do tema do gênero.

Observou-se, nos dois textos analisados, a ocorrência de dois posicionamentos discursivos: a) o personagem que assumia o primeiríssimo plano discursivo teve sua referência à direita do espaço de enunciação próximo ao centro, indicando um posicionamento no espaço análogo ao descrito por Massone (2000) na LSA; e b) todos os personagens, ao serem incluídos no contexto (re)atualizando-o, faziam-no pela direita do espaço sinalizador e

6 A palavra voz neste trabalho está sendo usada segundo o conceito bakhtiniano do termo. 
aí permaneciam até que nova atualização contextual fosse realizada; a pessoa já presente no contexto assumia um posicionamento à esquerda do sinalizador, sem haver sobreposição referencial; no entanto, eles se mantinham em um mesmo plano discursivo, havendo, assim, uma diferenciação na organização da LIBRAS se em comparação à da LSA.

Essa dinâmica interdiscursiva instaurada implica, assim, existência de movimento, variação no posicionamento dos personagens, e não localização estática das pessoas do discurso. Dessa forma, os personagens não apenas utilizavam o perímetro do semicírculo enunciativo, como também movimentavam-se pelo espaço de enunciação permitido pela língua.

\author{
Este movimento no espaço de enunciação pode ser observado no se- \\ guinte episódio ${ }^{7}$ :
}

7 Dada a materialidade visual-gestual da LIBRAS, o ideal seria que os exemplos fossem tomados e apresentados por intermédio de recursos visuais. Frente a impossibilidade de fazê-lo, optou-se pela transcrição das situações selecionadas, respeitando-se a organização específica da LIBRAS e não a tradução destes episódios para o português. Para a realização da transcrição, adotou-se o sistema proposto por Ferreira-Brito (1995), mais especificamente os itens referentes a: 1) uso de letras maiúsculas em português na transcrição das enunciações em LIBRAS; 2) transcrição dos verbos na forma infinitiva, já que não há flexão para modo e tempo verbal em LIBRAS; 3) representação dos pronomes pela notação pro + os números de 1 a 3 para as pessoas no singular e a notação $1 \mathrm{p}, 2 \mathrm{p}$ e $3 \mathrm{p}$ para as pessoas no plural; 4) para o verbos direcionais ou de concordância, utilizou-se os números de 1 a 3 para marcar as pessoas no singular e a notação 1p, 2p e 3p para as pessoas do plural (neste trabalho, as pessoas foram transcritas juntamente com os verbos, em subscrito e, em alguns momentos, ao invés da marcação pronominal proposta, foi utilizado o nome do personagem a fim de evitar ambigüidade referencial); 5) como na LIBRAS não há marcação de número e gênero, esta informação constou nas transcrições tendo como base o contexto da enunciação; 6) nas transcrições não serão encontrados artigos e preposições, pois os primeiros não existem em LIBRAS e os últimos são incorporados na organização gramatical espacial desta língua; 7) no caso do uso do alfabeto digital ou datilologia, as letras foram grafadas em maiúscula, em negrito, e foram separadas por um hífen; 8) quando foram utilizadas duas ou mais palavras em português para a expressão de um conceito, que em LIBRAS, é enunciado por um único sinal, as palavras apareceram ligadas por um hífen; 9) quando um único enunciado foi realizado com as duas mãos simultaneamente, um sinal foi colocado em cima do outro em linhas diferentes, estando na primeira, o sinal realizado com a mão direita (neste trabalho, quando, num único enunciado, houve a utilização das duas mãos não simultaneamente, manteve-se a mesma notação, respeitando-se a diferença temporal entre os sinais). Incluiu-se, neste estudo: 10) quando houve, nos enunciados, a manutenção do sinal ou da configuração de uma das mãos, essa continuidade foi marcada pela presença de linha pontilhada; 11) a pontuação utilizada pelo português escrito, a fim de garantir uma maior compreensão dos episódios, respeitando-se, para tal, as marcações discursivas da LIBRAS; 12) explicações sobre diferenciações no uso do espaço discursivo foram grafadas entre parênteses; 13) as expressões faciais e corporais do enunciador, por serem marcas discursivas de significação, foram transcritas em maiúscula e entre colchetes; 14) quando uma enunciação tiver 
Exemplo $1^{8}$ :

(...)

$\mathrm{N}$ : CHAPEUZINHO-VERMELHO-CAMINHA [FELIZ] (a direita do espaço de sinalização próximo ao centro). CANTAR

CV: TCHAU (vira para trás para despedir-se de sua mãe)

N: M-A-E TCHAU

CV: TCHAU (vira para trás). Chapeuzinho-Vermelho-caminha.

N: FLORESTA FLORES AO-LADO-DO-CAMINHO BONITO. PERFUMADO FLORESTA AO-LADO-DO-CAMINHO PERFUMADO

CV: Chapeuzinho-Vermelho-caminha-pela-floresta-segurando-a-cesta.

N.: CHEGAR HOMEM CHEGAR (a direita do espaço de sinalização). HOMEM ${ }^{\text {ENCONTRAR }}$ CHAPEUZINHO.

CV: assustar (a esquerda do espaço de sinalização)

Le: QUEM-É-VOCÊ?

CV: EU NOME MEU-SINAL CHAPEUZINHO-VERMELHO EU

(...)

Esquematicamente, esta dinâmica interdiscursiva pode ser representada como:

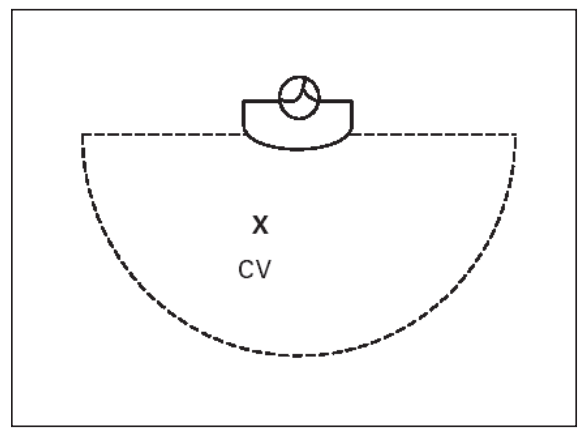

Chapeuzinho Vermelho caminha pela floresta

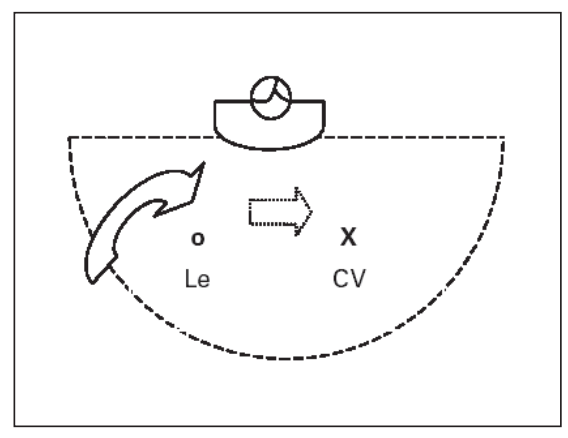

O lenhador entra em cena e encontra Chapeuzinho Vermelho

ocorrido por meio de aspectos discursivos não-verbais - a realização/encenação de uma ação e não sua verbalização - essa informação encontra-se em minúscula, respeitando-se a organização da LIBRAS.

8 Utilizou-se neste trabalho as iniciais: N, CV, Le, L, V, M, 3P e P1 para narrador, Chapeuzinho Vermelho, lenhador, lobo, vovó, mãe, três porquinhos e primeiro porquinho, respectivamente. 
Chapeuzinho Vermelho, representada pelo classificador de pessoa utilizado pela LIBRAS (configuração de mão $\mathrm{G} 1^{9}$ ), ao caminhar pela floresta, é mantida, pelo narrador, a direita do espaço de enunciação próximo ao centro, assumindo, desse modo, o primeiríssimo primeiro plano discursivo. Com a chegada do novo personagem (o lenhador) realizada pela direita do espaço de sinalização, Chapeuzinho Vermelho ganha novo locus discursivo e assume um posicionamento à esquerda do narrador. A menina permanecerá neste mesmo local do espaço quando em seu diálogo com o lobo na floresta (logo a seguir ao estabelecido com o lenhador), deslocando-se, novamente, à direita (primeiro plano discursivo) quando na casa da vovó.

Entende-se assim, essa dinâmica interdiscursiva como decorrente da nova entrada da menina "em cena" (que havia "cedido lugar" para o narrar da chegada e das ações do lobo na casa da vovó). Ou seja, nos dois textos analisados para este estudo, cada novo personagem que assumia o espaço discursivo, fê-lo pela direita, deslocando o que já se encontrava "em cena" para a esquerda. No entanto, este deslocamento do personagem não foi indicativo de um posicionamento que tivesse a configuração de fundo no contexto discursivo, diferenciando-se, assim, da organização espacial descrita por Massone (2000) na LSA. Ambos os personagens mantiveram-se num mesmo plano discursivo e seu posicionamento à direita e à esquerda no espaço de enunciação foi realizado conforme descrito para a localização das pessoas no espaço quando na marcação de referentes não-presentes (fisicamente) no contexto (cf.: Ferreira-Brito, 1995; Quadros, 1997; Quadros \& Karnopp, 2004).

O mesmo, porém, não pode ser dito no que se refere ao posicionamento espacial de objetos. Observou-se que o posicionamento das casas da vovó e dos porquinhos, de forma contrária, ocorreu, desde a primeira referência, à esquerda do espaço de sinalização. Este fato sugere haver, em LIBRAS, uma hierarquia espacial diversa quanto ao uso do espaço no caso de referência a pessoas e a objetos, estando, apenas estes últimos, à esquerda do espaço com caráter de fundo discursivo.

No entanto, como foram analisados apenas dois textos do gênero contos de fadas neste estudo, acredita-se que os dados obtidos não sejam sufi-

\footnotetext{
9 Mão fechada com dedo indicador estendido para cima, palma para frente (cf.: Ferreira-Brito,
} 1995). 
cientes para uma generalização quanto ao funcionamento discursivo da LIBRAS, como a feita por Massone (2000) na LSA. Entretanto, este dado mostra-se relevante para um conhecimento mais aprofundado da organização discursiva em LIBRAS e, portanto, merece ser melhor investigado em outros textos neste gênero e em outros gênero do discurso nesta língua.

Outro ponto observado diz respeito à distância imposta entre os personagens: esta também mostrou variações determinadas diretamente pela situação discursiva em questão.

Massone (2000) discutiu também que as diversas situações comunicativas (públicas, privada e íntima) e os diferentes registros (formal e informal) em LSA sofrem diferenciações que podem ser percebidas pelas dimensões espaciais, pela amplitude de realização do sinal e pelo perímetro que engloba o espaço sinalizador. Concluiu que um diálogo mais afetivo é realizado com uma aproximação maior dos corpos, enquanto que o distanciamento destes denotaria uma situação inversa. Embora Massone (2000) tenha reconhecido que este mesmo fato pode ser observado nas análises das línguas verbais-orais, apontou que na LSA este distanciamento dos corpos nas situações enunciativas "converte-se em um traço semântico que se distingue na amplitude do movimento, na possibilidade de extensão dos braços e na distância relativa dos corpos" (Massone, 2000: 108).

Nos textos analisados neste artigo observou-se, também, uma diferenciação no distanciamento entre os personagens e nos movimentos realizados na sinalização dependendo do contexto de produção dos enunciados, assinalando a apreciação valorativa da situação pelos personagens. Ou seja, Chapeuzinho Vermelho realizava movimentos amplos e fluentes ao dialogar com sua mãe e/ou com o lenhador. No entanto, seus movimentos alteraram-se consideravelmente quando ao se deparar com o lobo na floresta: ela se distanciou dele, seus sinais mostraram-se trêmulos e com amplitude reduzida, diminuindo, assim, a fluência de sua sinalização.

No que se refere à relação discursiva entre os personagens observou-se que esta se caracterizou pelo uso do discurso direto. Em sua grande maioria, o diálogo foi compreendido em seu sentido estrito, no qual interlocutores distintos apresentam a palavra e a contra-palavra numa relação tensa e de constante conflito (Bakhtin, 1929). Nestes diálogos não houve sobreposições de vozes: o discurso dos personagens apenas conhecia a si mesmo e a seu objeto, mantendo uma fronteira precisa e demarcada entre eles. 
Sua construção teve como base a primeira e a segunda pessoas do singular, marcadas pelo uso dos respectivos pronomes, pela direção do olhar e dos movimentos próprios da sinalização em relação aos referentes.

Conforme exposto na nota de rodapé $\mathrm{n}^{\circ} 3$, o olhar é usado, em LIBRAS, como um importante diferenciador das referências de segunda e terceira pessoas do discurso. Assim, no caso dos diálogos entre os personagens, este se dirigia sempre para o interlocutor, portanto, para a segunda pessoa do singular. Além disso, o posicionamento do corpo do sinalizador respeitou, nestes eventos, os tamanhos pressupostos dos personagens nas histórias infantis: Chapeuzinho Vermelho, por ser uma criança, é representada como sendo menor que o lenhador, um adulto, e menor que o lobo, "grande", "forte" e "alto" (o mesmo pode ser dito em relação aos porquinhos se em comparação com o lobo). Este fato determinou um direcionamento do olhar e dos movimentos de sinalização que tenderam ou para cima ou para baixo dependendo do interlocutor ou de seu posicionamento físico nos diferentes momentos da história.

Um exemplo no qual esta relação discursiva pode ser observada refere-se ao diálogo entre o lobo e o primeiro porquinho:

Exemplo 2:

(...)

N: L-O-B-O\#M-A-U PROCURAR FOME F-O-M-E.

PROCURAR. ${ }_{\text {LOBO }}$ ANDAR, VER ${ }_{\text {CASA }}$, CASA FRACA CASA, ESTRANHA.

OLHAR $_{\text {DENTRO-DA-CASA }}$ PORQUINHO DORMIR.

L: Pro1 COMER pro2! (olhando para o local do espaço de referência do porquinho)

N: PORQUINHO ACORDAR

$\mathrm{P} 1$ : gritar-assustado

L: Pro1 COMER pro2! (olhando para o local de referência do porquinho com o olhar direcionado levemente para baixo)

P1: ENTRAR NÃO-DÁ (olhando para o local de referência do lobo com o olhar levemente levantado)

L: Pro1 CONSEGUIR. ESPERAR... olhar-para-a-casa, balançar-os-braços, inflarbochechas, assoprar. Casa-desabar-a-sua-frente.

Observa-se, nas enunciações dos personagens, que não apenas há a marcação pronominal explicita de primeira e segunda pessoas, como tam- 
bém o direcionamento do olhar e a movimentação da sinalização como indicativo de quem está falando e com quem. Pereira \& Nakasato (2001) comentam que a direção do olhar para cima ou para baixo foi descrita por Lidell $(1995)^{10}$ em seu estudo sobre o narrar histórias em ASL. Os autores compreenderam que, nestes casos, a referência aos personagens é realizada como se os mesmos estivessem presentes no espaço de sinalização. Esta "presença" dos personagens pode ser observada, também, no tipo de movimentação de corpo realizada pelo sinalizador, pois quando ele assume as vozes dos personagens, seu corpo movimenta-se com maior liberdade tanto no espaço de sinalização quanto no próprio eixo vertical. Esta maior mobilidade pode ser percebida no primeiro exemplo quando o sinalizador indica Chapeuzinho Vermelho caminhando feliz pela floresta (em oposição ao mesmo fato narrado, no qual o corpo do sinalizador demonstra uma "rigidez" em sua movimentação ${ }^{11}$ ) e, no segundo exemplo, quando o lobo prepara-se para assoprar a casa dos porquinhos (balançar-os-braços, inflarbochechas) e a vê desabar a sua frente.

Um outro exemplo em que a marcação pronominal, o direcionamento do olhar e a movimentação do corpo indicam a presença das vozes dos dois personagens pôde ser observada, foi o diálogo entre a Chapeuzinho Vermelho e o lobo, quando ele já está disfarçado de vovó. Neste exemplo, no entanto, pôde-se perceber a existência do discurso bivocal presente nas enunciações do lobo.

Exemplo 312:

(...)

$\mathrm{N}$ : MENINA MENINA-CAMINHAR [FELIZ]. CHAPEUZINHO-VERMELHOCAMINHAR FLORESTA, FLORES-NO-CHÃO. [FELIZ] CHAPEUZINHOVERMELHO-ANDAR CAMINHO (o caminho é descrito primeiro a direita do espaço de sinalização, terminando à esquerda). CASA. CHAPEUZINHOVERMELHO-CHEGAR $_{\text {CASA }}$ (a direita do espaço de sinalização)

CV: bater-na-porta.

segurar-cesta

10 Os autores fizeram referência ao seguinte trabalho: Lidell, S. K. (1995) Tokens and surrogates. In: Emmorey, K.; Reilly, J. (eds.) Language, Gesture and Space. Hillsdale, NJ: Lawrence Erlbaum Associates Inc.

11 Os aspectos enunciativos próprios do narrador serão discutidos em maior detalhe a seguir.

12 Neste exemplo, as falas do lobo foram numeradas a fim de auxiliar a discussão das mesmas. 
$\mathrm{N}:{ }_{\text {LOBO }}$ COBERTO (a esquerda do espaço de sinalização)

$\mathrm{L}_{1}$ : PODER ENTRAR esconder-rosto-coberta.

CV: abrir-porta. Pro2 VOZ DIFERENTE pro2 ${ }^{13}$ ?

$\mathrm{L}_{2}$ : Pro1 DOENTE ENTENDER? Esconder-rosto-coberta

CV: [PENSATIVA] colocar-cesta-no-chão. Pro2 ANTES VOVÓ MINHA NÃOTER ORELHAS-GRANDES, pro2 ORELHAS-GRANDES, POR-QUE? COMO?

$\mathrm{L}_{3}$ : ME-PEGOU ${ }^{14}$...! (olhando para o lado oposto à Chapeuzinho Vermelho) PORQUE pro1 OUVIR BEM pro2 ENTENDER? Esconder-rosto (vira novamente para o lado oposto à Chapeuzinho Vermelho). ME-PEGOU...!

CV.: [PENSATIVA]... ESTRANHO! ANTES MINHA VOVÓ NÃO-TER OLHOSGRANDES, pro2 TER OLHOS-GRANDES. ESTRANHO pro2!

$\mathrm{L}_{4}$ : ME-PEGOU DIFERENTE...! PORQUE OLHOS-GRANDES ${ }_{1} \mathrm{VER}_{2}$ BEM ENTENDER?

CV: [PENSATIVA]... MINHA ANTES VOVÓ NÃO-TER NARIZ-GRANDE, pro2 TER NARIZ-GRANDE, POR-QUE? COMO?

$\mathrm{L}_{5}$ : PORQUE pro1 CHEIRAR BEM pro2 ENTENDER?

CV: [PENSATIVA] olhar ${ }_{\text {vovó }}$ DIFERENTE pro2! ANTES VOVÓ NÃO-TER DENTES-GRANDES, pro2 TER DENTES-GRANDES, POR-QUE?

$\mathrm{L}_{6}:$ [NERVOSO]! PORQUE DENTES-GRANDES, PORQUE pro1 COMER BEM pro2 ENTENDER? Abrir-boca

(...)

Pode-se perceber, nestes exemplos, a marcação pronominal realizada de maneira explícita, pelo uso dos pronomes de primeira e segunda pessoas, pela incorporação pronominal nos verbos que aceitam conjugação de pessoa e número ( $\mathrm{VER}_{2}-$ eu ver você $\left.{ }^{15}\right)$, pelo direcionamento do olhar para o interlocutor e pela direção dos movimentos realizados.

No entanto, este episódio aponta ainda para um outro processo discursivo: foi possível notar nas enunciações do lobo (principalmente nas falas $\mathrm{L}_{3}$ e $\mathrm{L}_{4}$ do personagem) a presença de duas vozes - a dele e a da Chapeuzinho Vermelho antecipada - , introduzida em sua enunciação na forma de discurso interior e realizada através da mudança na direção do

13 Todas as enunciações de Chapeuzinho Vermelho, neste exemplo, foram realizadas com o olhar direcionado para seu interlocutor (portanto, a esquerda) e deslocado levemente para baixo. As do lobo também tiveram o olhar direcionado ao interlocutor (a direita) deslocado levemente para cima.

14 No sentido de ter sido descoberto, de Chapeuzinho Vermelho ter percebido tratar-se do lobo.

15 Ver explicação sobre estes verbos na nota $n^{\circ} 7$. 
olhar para o lado oposto ao que Chapeuzinho Vermelho se encontrava. Este fato pode ser observado quando ele enuncia para si o fato da menina ter percebido que ele não era a vovó - ME-PEGOU (virando a cabeça e/ou escondendo-se sob a coberta) - revelando a consciência que tem de si como diferente e antecipando o que não foi dito por Chapeuzinho Vermelho esta não é a minha vovó. Ao interpretar a estranheza de Chapeuzinho Vermelho quanto à mudança na aparência da vovó - a palavra do outro sobre si mesmo - o lobo procurou destruir esta palavra, buscando convencê-la de que sua impressão estava equivocada.

Há, assim, no discurso do lobo o esboço da apreciação do outro suscitando conflito e embaraço e, portanto, instaura-se um choque dialógico, de duas consciências, surgidas de duas réplicas que se fundiram; há "o cruzamento e a interseção de duas consciências em cada elemento da consciência e do discurso, em suma, a interferência de vozes no interior do átomo" (Bakhtin, 1929: 212).

Dessa forma, embora o discurso utilizado pelos personagens caracterize-se pelo tipo direto, com fronteiras delimitadas, foi possível perceber a presença do discurso do outro em suas enunciações e da dialogicidade constitutiva da linguagem.

No caso da voz do narrador, observou-se um funcionamento discursivo diverso ao utilizado pelos personagens. No que se refere ao posicionamento espacial, pôde-se notar que todas as suas enunciações foram realizadas a partir de um único e mesmo lugar no espaço de sinalização - no centro do raio do semicírculo enunciativo -, marcando com essa "rigidez" referencial, um distanciamento do jogo dinâmico de posicionamentos espaciais assumidos pelos personagens. Os movimentos realizados no espaço pelo narrador ficaram restritos à rotação na orientação de seu corpo no eixo vertical, necessários para a introdução dos personagens e/ou para situá-los nas diversas atualizações contextuais.

O olhar utilizado pelo narrador também se diferenciou daquele dos personagens: embora pela própria organização e materialidade da LIBRAS o narrador necessite dirigir seu olhar para os personagens como marca discursiva de referência, esse era preciso a um determinado local do espaço de sinalização (aquele de referência dos diferentes personagens no contexto em que eles se faziam presentes) e, em seguida, voltava-se para frente, dirigindo-se ao interlocutor que o vê narrar a história. 
Além disso, em todas as suas enunciações, o narrador fez uso do discurso indireto e, portanto, utilizou-se de um tipo discursivo diferente do adotado pelos personagens. Como exemplo, foi selecionado o seguinte episódio relativo à introdução do texto dos Três Porquinhos:

\section{Exemplo 4:}

N.: FLORESTA CASA, AQUI M-A-E PORQUINHOS (à direita do enunciador). 3 FILHOS, 3 PORQUINHOS (a esquerda do enunciador).

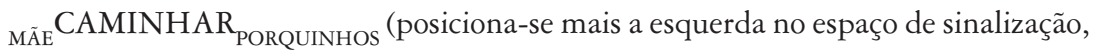
mas mantém-se a direita se em relação aos porquinhos). Pro3P (aponta para os porquinhos e olha para frente), 3 PORQUINHOS, CRESCER JÁ (olha para frente),

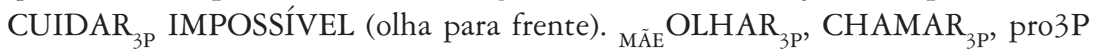
TRABALHAR IR. (olha para frente) 3 PORQUINHOS (olha a direita balançando a cabeça)

OK (olha para frente).

ABRIR-PORTA SAIR

M-A-E TCHAU. TRÊS-PORQUINHOS

TCHAU (olha para a direita e para frente)

-SAEM-ANDANDO (olha para frente e para a esquerda). PRIMEIRO PREGUIÇOSO VONTADE

TRABALHAR NÃO, PREGUIÇOSO. SEGUNDO MAIS-OU-MENOS VONTADE ESTUDAR, MAIS-OU-MENOS. TERCEIRO INTELIGENTE, VONTADE TRABALHAR-MUITO, MUITO-INTELIGENTE TERCEIRO. TRÊS-PORQUINHOS-SE-SEPARAM (mantendo a localização a esquerda do sinalizador).

\section{(...)}

Neste exemplo, o uso do discurso indireto pelo narrador pôde ser percebido a partir de duas marcações discursivas diferentes: pela nomeação dos personagens antes de sua enunciação (3 PORQUINHOS OK; M-A-E TCHAU) e pela mudança de olhar, que se desvia do local de referência dos personagens para a frente.

Este jogo de olhar para a referência e para a frente possibilitou, ao narrador, apagar as fronteiras do discurso do outro (da mãe), assumir uma posição discursiva fluída, unindo sua voz à linguagem dos personagens e, desse modo, em sua fala, pôde-se fazer presente também a voz da mãe dos porquinhos quando ela avalia o fato de seus filhos terem crescido e, portanto, ser impossível para ela criá-los sozinha. O discurso do outro e o contexto de transmissão foram apresentados numa inter-relação dinâmica, 
num reflexo da "dinâmica da inter-relação social dos indivíduos na comunicação ideológica verbal" (Bakhtin/Volochinov, 1929: 148). Essa construção discursiva difere daquela utilizada pelos personagens (conforme comentado anteriormente).

No que tange ao distanciamento físico-espacial do narrador, este não o impossibilitou de assumir uma posição ideológica sobre a situação, imprimindo, em sua enunciação, seu acento apreciativo particular. No exemplo acima, esta apreciação valorativa do narrador pode ser percebida nas enunciações: "primeiro [porquinho] preguiçoso", "segundo [porquinho] tem mais ou menos vontade de estudar" e "terceiro [porquinho] inteligente".

Desse modo, pode-se dizer que, pelo posicionamento do corpo do narrador e pela mudança no direcionamento do olhar, foi possível a ele garantir, discursivamente, que sua voz não se sobrepusesse à dos personagens, na medida em que, pela própria materialidade da LIBRAS, as ações realizadas pelos personagens no decorrer do texto (sejam elas narradas ou "realizadas" pelos próprios personagens), eram, em alguns momentos, desenvolvidas pela "encenação" dos fatos ocorridos. A fim de melhor esclarecer este ponto será apresentada a transcrição do episódio em que o lobo invade a cada da vovó para esperar Chapeuzinho Vermelho com a intenção de devorá-la.

Exemplo 5:

(...)

$\mathrm{N}$ :

LOBO-MAU-CAMINHAR-RÁPIDO. LOBO-MAU-

CHAPEUZINHO-VERMELHO-CAMINHAR-DEVAGAR

CAMINHAR-MAIS-RÁPIDO. CORRER. LOBO-MAU-CAMINHAR-MAISRÁPIDO CHAPEUZINHO-VERMELHO-CAMINHAR-

DEVAGAR

${ }_{\text {LOBO }}$ CORRER ${ }_{\text {LOBO }}$ CORRER $_{\text {LOBO }}$ CORRER. LOBO-MAU-CAMINHAR-RÁPIDO. CAMINHO (o caminho é descrito primeiro a direita do espaço de sinalização, terminando a esquerda). CASA LOBO-CHEGAR ${ }_{\text {CASA }}$ (chega a direita da localização da casa). cansar, olhar-para-trás. LOBO-PARAR-EM-FRENTE-A-PORTA. VOVÓ ESTAR DOENTE COBERTA (tronco em rotação vertical a esquerda). PORTA LOBO ENTRAR-CORRENDO. vovóASSUSTAR (tronco em rotação vertical a esquerda). LOBO-CORRER VOvó ${ }_{\text {LOBO }}$ ENCONTRAR $_{\text {vOvó • vovó }}$ ASSUSTAR (tronco em rotação

VOVÓ

vertical a esquerda). Lово $_{\text {SEGURAR }}$ vovó-PELOS-BRAÇOS (desloca o tronco em direção ao local de referência da vovó e volta ao seu posicionamento inicial). 


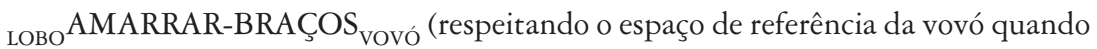
ao amarrá-la). vovó GRITAR vovó GRITAR vovó GRITAR (tronco em rotação verti-

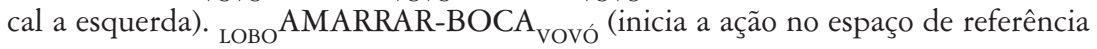
da vovó e termina no espaço do narrador realizada no próprio corpo). ${ }_{\text {LOBO }}$ SEGU-

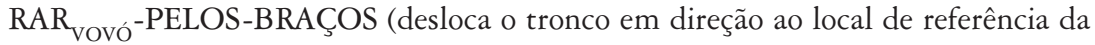
vovó e volta ao seu posicionamento inicial). ${ }_{\text {LOBO }} \mathrm{OLHAR}_{\text {ESPACCO }}-$ SEGURANDO $_{\text {VO- }}$ vó-PELOS-BRAÇOS. ONDE? ${ }_{\text {LOBO }}$ SEGURAR ${ }_{\text {vovó }}$-PELOS-BRAÇOS (desloca o tronco em direção ao local de referência da vovó e volta ao seu posicionamento inicial). ARMÁRIO (a esquerda do espaço de enunciação) COLOCAR vOvó $^{-D E N T R O . ~}$ FECHAR-PORTA, RIR (olha para frente)

L: Pro1 IDÉIA! ROUPA.... Vestir-roupa, colocar-touca, colocar-óculos. Pro3 VERMELHO MENINA PENSAR pro1 VERDADE VOVÓ. Rir, esfregar-as-mãos. Deitar. Cobrir-se

Neste exemplo da história da Chapeuzinho Vermelho, pode-se observar que o narrador, ao contar as "ações" realizadas pelo lobo na casa da vovó, manteve suas enunciações em discurso indireto, unindo sua voz à dos personagens. Incorporou as ações do lobo e da vovó realizando expressões faciais condizentes com elas; no entanto, a movimentação de seu corpo indicou marcas discursivas particulares, que se diferenciam daquela dos personagens: os movimentos realizados foram, unicamente, de seu tronco e no início da ação (como marca discursiva de referência ao personagem que a estava realizando), retornando ao centro do espaço de sinalização na finalização da mesma. Além disso, ao final da narração do episódio, o sinalizador desvia seu olhar para a frente, marcando, pelo direcionamento do olhar, a pessoa do discurso.

A inclusão da voz do lobo na história é realizada em seguida à narração de suas ações pelo sinalizador e, essa diferenciação das vozes, pode ser observada pela presença do discurso direto, em primeira pessoa, utilizado pelo lobo (Tive uma idéia! A roupa...; Ela, Chapeuzinho Vermelho, irá pensar que eu sou a vovó de verdade!), pela maior liberdade na movimentação do corpo do sinalizador (seu tronco é deslocado para a esquerda do semicírculo de sinalização para pegar a roupa, os óculos e a touca da vovó e, na "encenação" do vestir cada um dos utensílios, as expressões faciais e a liberdade de movimentos indicam os atos realizados) e pelo olhar (direcionado para cima, para a esquerda e/ou para a direita, mas nunca para frente). 
Pode-se dizer, assim, que nos dois textos analisados para este estudo, a separação das vozes do narrador e dos personagens foi realizada pelo uso diferenciado do espaço de enunciação, pela presença do discurso indireto (do narrador) e do direto (dos personagens), pelas marcas discursivas verbais (uso dos pronomes pessoais) e não-verbais (jogo de olhar, direcionamento dos movimentos dos sinais e movimentação que cada um realiza no espaço de enunciação e no eixo vertical do corpo).

\section{Conclusão}

O presente estudo, desenvolvido à luz da teoria enunciativa bakhtiniana, buscou compreender a língua em funcionamento, ou seja, a linguagem em sua dimensão discursiva. A partir da consideração de que o discurso se constrói a partir de gêneros discursivos que variam e se constituem nas diversas esferas de atividade humana, este trabalho se propôs a estudar o funcionamento da LIBRAS no gênero contos de fadas.

As análises realizadas, embora ainda iniciais, apontaram alguns aspectos relevantes sobre a organização discursiva da LIBRAS quando em seu uso neste gênero, particularmente no que se refere à dinâmica interdiscursiva que o constitui. Melhor dizendo, permitiu a compreensão de como os discursos do narrador e dos personagens presentes nos textos são construídos, como eles se diferenciam quanto aos aspectos composicionais, como assimilam o discurso do outro e como se inter-relacionam entre si e com o todo textual para o tratamento do tema.

A partir da análise de dois textos - Chapeuzinho Vermelho e Os Três Porquinhos - foi possível perceber que os personagens têm suas vozes marcadas segundo o lugar no espaço de enunciação que assumem; no entanto, estes locais variam segundo o contexto discursivo assim como são por ele determinados. Dessa forma, eles não apresentam um posicionamento fixo no espaço, mas sim, movimentam-se neste espaço posicionando-se a direita do sinalizador sempre que entram "em cena", deslocando aquele que já se encontra presente no contexto enunciativo para um posicionamento a esquerda do enunciador. Estes posicionamentos distintos, entretanto, não interferem no plano discursivo dos personagens no contexto da história. A diferenciação no plano discursivo é feita, apenas, quando na inclusão de objetos ao contexto discursivo, que assumem um posicionamento à esquerda no espaço de enunciação em caráter de fundo discursivo. 
O direcionamento do olhar, as expressões faciais, a direção dos sinais e os movimentos de corpo do sinalizador quando as vozes dos personagens fazem-se presentes, são importantes marcas discursivas da(s) pessoa(s) do discurso e indicativas das separações das vozes do narrador e dos personagens. Observou-se, também, que, dependendo da avaliação apreciativa que os personagens fazem da situação, sua sinalização pode vir a alterar-se quanto à fluência e amplitude, além de haver um maior distanciamento ou aproximação dos personagens quando estes se encontram frente a frente.

No que se refere ao narrador, observou-se que ele adota uma posição fixa no espaço de enunciação - centro do raio do semicírculo - fazendo uso de movimentos restritos ao eixo vertical de seu corpo. Esta "rigidez" espacial e de movimentação do corpo lhe possibilita garantir um certo distanciamento da dinâmica interdiscursiva instaurada entre os personagens, mas, no entanto, não o impede de posicionar-se discursivamente apresentando sua própria avaliação apreciativa da situação.

Percebeu-se, também, que o tipo de discurso adotado pelos personagens é o direto e, em sua maioria, o diálogo é compreendido em seu sentido mais estrito; porém, é possível observar neles a presença constante da palavra do outro, às vezes antecipada no discurso de quem fala. Esta relação dialógica, essência do discurso, apresenta uma construção distinta se o foco de observação mudar para o narrador, pois ele utiliza-se sempre o discurso do tipo indireto. No entanto, observa-se também presente em suas enunciações a voz do outro e sua acentuação valorativa, numa interação discursiva constante entre os personagens, as situações e o todo textual.

Conforme exposto anteriormente, este estudo pretendeu a realização de uma leitura inicial dos processos discursivos próprios do gênero contos de fadas em LIBRAS e, portanto, ele não se encerra nele próprio. Na verdade, os dados aqui discutidos apontam para a necessidade de continuidade, de um maior aprofundamento nos estudos discursivos em LIBRAS, a fim de que os achados aqui apresentados sejam complementados e melhor conhecidos tanto no gênero contos de fadas, como nos diversos outros gêneros discursivos em LIBRAS.

E-mail: analodi@uol.com.br

Recebido em julho de 2003 Aprovado em março de 2004 


\section{ReFerênCias Bibliográficas}

Alves, A. C. C. \& L. B. Karnopp. 2002. O surdo como contador de histórias. In: A. C. B. Lodi, K. M. P. Harrison, S. R. L. de Campos \& O. Teske. Orgs.. Letramento e Minorias. Porto Alegre: Mediação, 71-75.

Amaral, M. A.; A. Coutinho; M. R. D. Martins. 1994. Para uma Gramática da Lingua Gestual Portuguesa. Lisboa: Editorial Caminho.

Bakhtin, M. 1929. Problemas da Poética de Dostoievski, $2^{\mathrm{a}}$ ed. revista. São Paulo: Editora Forense Universitária, 1997. .1934-1935/1975. O discurso no romance. In: Questões de Literatura e de Estética: A teoria do romance, $4^{\mathrm{a}}$ ed. São Paulo: HUCITEC, 1998, 71-163. .1952-1953/1979. Os gêneros do discurso. In: Estética da

Criação Verbal, $3^{\mathrm{a}}$ ed. São Paulo: Martins Fontes, 2000, 277-326. .1970-1971/1979. Apontamentos. In:

Verbal, $3^{\text {a }}$ ed. São Paulo: Martins Fontes, 2000, 369-397.

Bakhtin, M./ Volochinov, V.N. 1929. Marxismo e Filosofia da Linguagem, $9^{a}$ ed. São Paulo: HUCITEC, 1999.

Behares, L. E. 1993. Implicações neuropsicológicas dos recentes descobrimentos na aquisição de linguagem pela criança surda. In: M. C. Moura; A. C. B. Lodi \& M. C. da C. Pereira. Orgs.. Lingua de Sinais e Educação do Surdo. Série de Neuropsicologia, vol. 3. São Paulo: Tec Art, 41-55.

Biblioteca Virtual do Estudante Brasileiro: Chapeuzinho Vermelho - a surda. www.bibvirt.futuro.usp.br/index.html?principal.html\&2.

BraIt, B. 1997. Bakhtin e a natureza constitutivamente dialógica da linguagem. In: (org.) Bakbtin, Dialogismo e a Construção do Sentido. Campinas: Editora da UNICAMP, 91-104.

Culler, J. 1979. As Idéias de Saussure. São Paulo: Cultrix.

Emmorey, K.; U. Bellugi \& E. Klima .1993. Organização neural da língua de sinais. In: M. C. Moura; A. C. B. Lodi \& M. C. da C. Pereira. Orgs. Lingua de Sinais e Educação do Surdo. Série de Neuropsicologia, vol. 3. São Paulo: Tec Art, 19-40.

Ferreira-Brito, L. 1995. Por uma Gramática de Lingua de Sinais. Rio de Janeiro: Tempo Brasileiro/ UFRJ, Departamento de Lingüística e Filologia. 
GeSueli, Z. M. 2000. A intertextualidade na elaboração narrativa em língua de sinais. In: C. B. F. de Lacerda \& M. C. R. de Góes. Orgs.. Surdez: Processos educativos e subjetividade. São Paulo: Lovise, 95-112.

Johnson, R. E. 1994. Prefácio. In: M. A. Amaral; A. Coutinho \& M. R. D. Martins. Para uma Gramática da Língua Gestual Portuguesa. Lisboa: Editorial Caminho, 13-18.

Klima, E. S. \& U. Bellugi. 1979. The Signs of Language. Cambridge: Harward University Press.

Machado, I. A. 1997. Os gêneros e o corpo do acabamento estético. In: B. Brait. Org. Bakhtin, Dialogismo e a Construção do Sentido. Campinas: Editora da UNICAMP, 141-158.

Massone, M. I. 1993. O lingüista ouvinte frente a uma comunidade surda e ágrafa: Metodologia da investigação. In: M. C. MourA; A. C. B. Lodi \& M. C. da C. PereirA. Orgs. Lingua de Sinais e Educação do Surdo. Série de Neuropsicologia, vol. 3. São Paulo: Tec Art, 72-93.

. 2000. Aspectos discursivos y semióticos de la lengua de señas argentina. El Bilingüismo de los Sordos, v.1, $\mathbf{n}^{\mathbf{0}}$ 4. Santa Fé de Bogotá, 102-109.

Pereira, M. C. da C. 2001. A expressão da coesão nas narrativas de histórias por crianças surdas através da língua de sinais brasileira. Boletim da ABRALIM, v.26, $\mathbf{n}^{\circ}$ especial II, 371-373.

. 2002. Papel da língua de sinais na aquisição da escrita por estudantes surdos. In: A. C. B. Lodi, K. M. P. Harrison, S. R. L. de Campos \& O. Teske. Orgs.. Letramento e Minorias. Porto Alegre: Mediação, 47-55.

Pereira, M. C. da C. \& R. Nakasato. 2001. Aquisição de narrativas em língua de sinais brasileira. Letras de Hoje, v.36, $\mathbf{n}^{\circ}$ 3, 355-363.

. 2002. A língua de sinais brasileira em funcionamento - reflexão sobre o uso da língua de sinais brasileira no discurso narrativo de criança surda. Intercâmbio, v.XI, 69-76.

Poizner, H.; E. S. Kuima \& U. Bellugi. 1987. What the Hands Reveal about the Brain. Cambridge, MA: MIT Press.

Quadros, R. M. de. 1997. Educação de Surdos: A aquisiz̧ão da linguagem. Porto Alegre: Artes Médicas.

Quadros, R. M. de \& L. B. Karnopp. 2004. Lingua de Sinais Brasileira: Estudos lingüísticos. Porto Alegre: Artmed Editora.

Rée, J. 1999. I See a Voice: Deafness, language and the senses - a philosophical history. New York: Metropolitan Books. 
SÁ, N. R. L. de. 1998. O discurso surdo: a escuta dos sinais. In: C. Skliar. Org.. A Surdez: Um olhar sobre as diferenças. Porto Alegre: Mediação, 169-192.

Souza, R. M. de. 1998. Que Palavra que Te Falta? São Paulo: Martins Fontes. Stokoe, W. 1960. Sign Language Structure: An outline of the visual communication systems of the american deaf. Studies in Linguistics, $\mathrm{n}^{\circ} 8$. University of Buffalo.

Tezza, C. 1997. A construção das vozes no romance. In: B. Brait. Org.. Bakbtin, Dialogismo e a Construção do Sentido. Campinas: Editora da UNICAMP, 219-228. 